\title{
Features of migraine aura in teenagers
}

\author{
Igor Petrusic $2^{*}$, Vera Pavlovski ${ }^{2}$, Dragana Vucinic ${ }^{1}$ and Jasna Jancic ${ }^{1,2}$
}

\begin{abstract}
Background: Complex migraine aura in teenagers can be complicated to diagnose. The aim of this study was to present detailed features of migraine aura in teenage migraineurs.

Methods: This cross-sectional study was conducted in the period from 2008 till 2013. A total number of 40 teenage migraineurs (20 females and 20 males) met criteria for this study. The patients were interviewed using a specially designed questionnaire for collecting data about migraine aura features. Main outcome measures were frequency of visual, somatosensory and higher cortical dysfunction (HCD) symptoms in teenage migraineurs population during the aura, and also within each individual.

Results: Visual aura was reported in every attack, followed by somatosensory (60\%) and dysphasic (36.4\%) aura. Scintillating scotoma and blurry vision were mostly reported and predominant visual symptoms. The most common somatosensory symptom was numbness in hand. HCD were reported by $22(55 \%)$ patients. Slowed speech was mostly reported symptom of HCD, followed by dyslexia, déjà vu phenomenon, color dysgnosia, and dyspraxia. In patients with HCD, aura frequency per year ( $6.18 \pm 3.17$ vs. $3.33 \pm 2.03, p=0.003)$ and prevalence of somatosensory symptoms (77.3\% vs. 38.9\%, $\mathrm{p}=0.014)$ were significantly higher than in patients without HCD.
\end{abstract}

Conclusions: Aura symptoms vary to a great extent in complexity in teenage migraineurs. Consequently, results obtained in this study provide useful information for clinicians when faced with unusual migraine aura.

Keywords: Migraine aura; Higher cortical dysfunction; Teenagers

\section{Background}

The estimated overall mean prevalence of migraine in children and adolescents worldwide was $7-11 \%$ [1]. Thereof, $25 \%$ of patients with migraine experience an aura [2]. Migraine aura is commonly considered to precede headache [3]. Visual auras are the most common, followed by somatosensory, and then dysphasic auras [4]. Motor aura is the least common and is a defining feature of hemiplegic migraine [5].

Migraine aura is thought to arise due to a change in cortical neural excitability and function [6]. Cortical spreading depolarization followed by cortical spreading depression (CSD), mostly originates in the occipital region [7]. The involvement of other cortical areas beyond the occipital region could be assumed because of the existence of somatosensory and memory clinical features during the aura in some patients $[8,9]$.

\footnotetext{
*Correspondence: ip7med@yahoo.com

${ }^{2}$ Faculty of Medicine, University of Belgrade, Doktora Subotica 8, 11000 Belgrade, Serbia

Full list of author information is available at the end of the article
}

Diagnosis of migraine in the developmental age is more difficult and associated with imprecise description of the symptoms. Moreover, acute confusional migraine is primarily seen in children and adolescents [10]. The confusional state often manifests with a wide diversity of cortical dysfunctions, such as speech difficulties, amnesia, dysgnosia and dyspraxia [11]. Knowledge of migraine aura symptoms, clinical differences associated with developmental age and features are very important in differentiation with other disorders imitating migraine [12].

This study represents an attempt to present detailed features of migraine aura in teenagers. Furthermore, the aim of this study was to evaluate the frequency and types of higher cortical dysfunctions (HCD) that occur during the aura.

\section{Methods}

Total of 67 teenagers having migraine with aura, treated from the beginning of 2008 to the end of 2013 (six years), at the Clinic of Neurology and Psychiatry for Children and Youth, Medical Faculty, University of Belgrade, were called to participate in this study. The diagnosis was based

\section{它 Springer}


on the International Classification of Headache Disorders criteria [13]. Excluding criteria were: other neurological diseases, motor aura symptoms [13], chronic migraine and patients who did not respond to a call. Forty patients who met inclusion criteria have accepted to participate in this study. A special questionnaire (Table 1) was designed to collect data on migraine aura features and HCD during the aura. Positive responses to each question of designed questionnaire were followed by the sub-questions for the purpose of collecting information how long this symptom lasts, when this symptom starts in comparison to beginning of headache, how frequent this symptom is present in aura (in percentage) and whether symptom develops gradually. The patients were interviewed by a doctor (I.P. or V.P.), experienced in headache research. Research protocol of this study was approved by the review board of the Clinic of Neurology and Psychiatry for Children and Youth, Medical Faculty, University of Belgrade.

The data are presented as arithmetic mean values \pm SD or as percentages. For analysis purpose, we formed a

\section{Table 1 Study questionnaire}

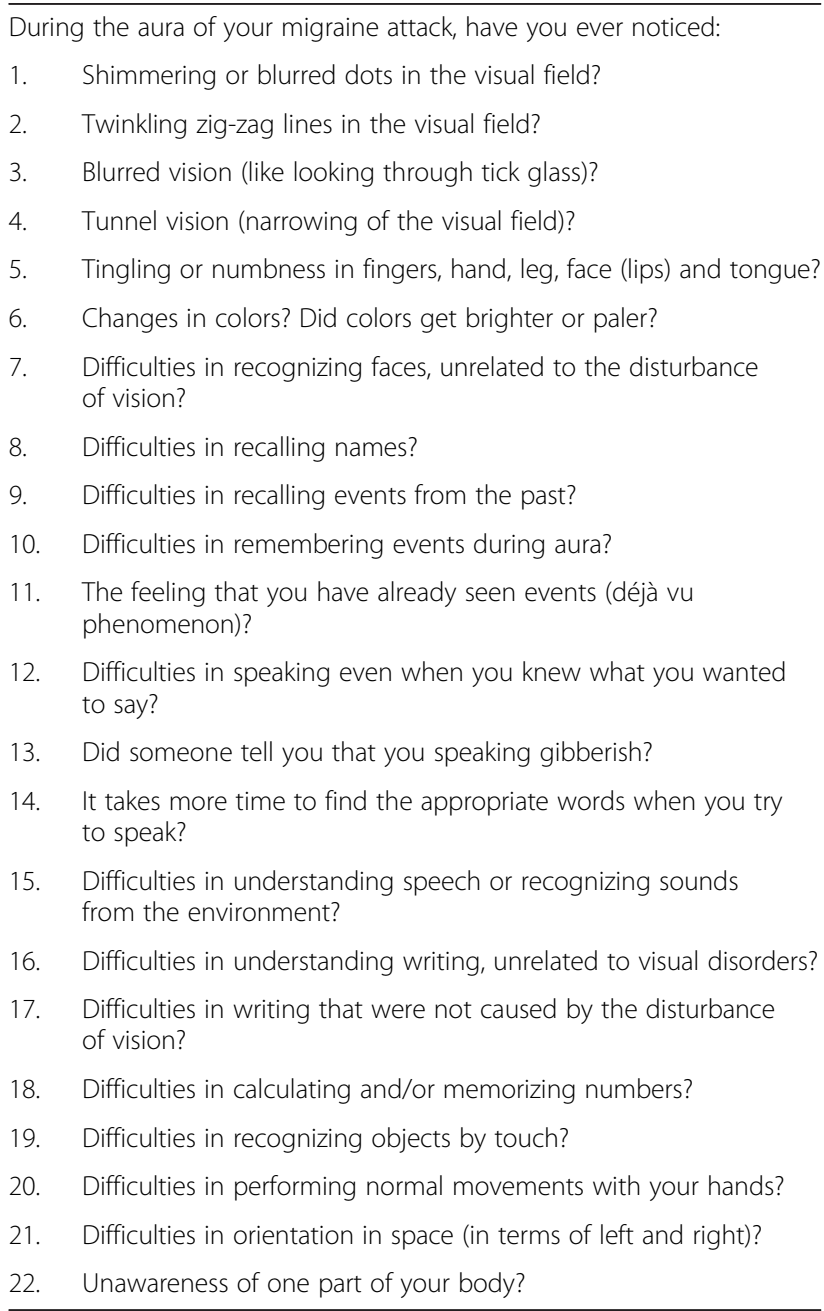

group of patients who experienced one or more HCD symptoms during the aura (HCD group) and a group of patients who did not experience HCD (Standard aura group). Independent samples t test was used to compare the age of patients and the age at the time of the onset of migraine with aura; Chi squared test was used to compare gender, number of patients who reported somatosensory symptoms in general and who reported numbness in hand; Fisher's exact test was used to compare the number of patients who reported numbness of arm, leg, tongue, face and lips; and the Mann-Whitney $\mathrm{U}$ test was used to compare aura duration and the number of auras per year between the groups. The significance level for the analysis was set beforehand at $5 \%(\mathrm{p}<0.05)$.

\section{Result}

The study included 20 females and 20 males, aged $16.2 \pm 2.0$ (range 13-19) years, who experienced migraine with aura. Fifteen (37.5\%) patients had visual aura only; 10 (25.0\%) patients had visual and somatosensory auras; and 15 (37.5\%) patients had visual with/or without somatosensory and with dysphasic aura.

Visual and somatosensory symptoms of aura in teenage migraineurs are described in Table 2. All patients had one or more visual symptoms. Scintillating scotoma was the most commonly reported (67.5\%) and predominant (94\%) visual symptom during the aura. Somatosensory symptoms were less common than visual with occurrence of $60 \%$ in patients. Most common was numbness in the left hand or both hands ( 2 patients) reported in 21 patients (52.5\%), followed by numbness in: lips and/or face (30\%), tongue $(27.5 \%)$, and legs (15\%). Two patients had acute onset visual aura, followed by short presentation of somatosensory symptoms and HCD. Also, two patients had prolonged visual aura, who reported gradual developing of somatosensory and dysphasic symptoms. Overall, in ten patients migraine aura proceeded during headache for $12.6 \pm 10.2$ (range 3-30) minutes and four patients reported period of $7.5 \pm 2.9$ (range 5-10) minutes between migraine aura and onset of headache. Twenty-six patients reported onset of headache immediately after finish of aura.

HCD were reported by 22 (55\%) patients in this study. A detailed description of HCD during the aura in teenage migraineurs analyzed group (40 patients) was given in Table 3. The majority of patients with HCD during the aura reported one, two, or four HCD symptoms, as shown in Figure 1. Slowed speech was the most usually reported (27.5\%) symptom of HCD during the aura, followed by dyslexia (25\%), déjà vu phenomenon (22.5\%), color dysgnosia (20\%), and dyspraxia (20\%). Prosopagnosia was reported in one (2.5\%) patient, while difficulties in understanding speech or recognizing sounds and difficulties in writing were not reported. Color dysgnosia, slowed 
Table 2 Visual and somatosensory symptoms during the aura

\begin{tabular}{lcccc}
\hline $\begin{array}{l}\text { Visual and somatosensory } \\
\text { aura features }\end{array}$ & $\begin{array}{c}\text { Number of patients } \\
\mathbf{n}=\mathbf{4 0}(\%)\end{array}$ & $\begin{array}{c}\text { Onset time } \mathbf{X} \pm \text { SD } \\
(\mathbf{m i n}-\mathbf{m a x})\end{array}$ & $\begin{array}{c}\text { Time duration } \\
\mathbf{X} \pm \text { SD (min-max) }\end{array}$ & $\begin{array}{c}\text { Frequency } \mathbf{X} \pm \text { SD } \\
(\mathbf{m i n}-\mathbf{m a x})\end{array}$ \\
\hline Scintillating scotoma & $27(67.5)$ & $21.24 \pm 15.87(25-60)$ & $18.67 \pm 16.62(2-75)$ & $94.26 \pm 17.25(25-100)$ \\
Zig-zag lines & $10(25)$ & $23 \pm 12.06(5-45)$ & $19.5 \pm 12.12(5-45)$ & $90 \pm 23.09(30-100)$ \\
Blurry vision & $24(60)$ & $22.22 \pm 12.12(2-45)$ & $19.29 \pm 14.53(2-45)$ & $85 \pm 27.54(10-100)$ \\
Tunnel vision & $16(40)$ & $24.69 \pm 14.54(5-60)$ & $18.44 \pm 12.48(5-60)$ & $74.38 \pm 35.02(10-100)$ \\
Somatosensory symptoms & $24(60)$ & $22.06 \pm 17.3(2-60)$ & $17.5 \pm 16.9(2-60)$ & $62.5 \pm 31.21(10-100)$ \\
\hline
\end{tabular}

Onset time - aura onset in regard to beginning of headache expressed in minutes; Time duration - expressed in minutes; Frequency - frequency of symptom compared to all experienced auras in individual (expressed in percentages).

speech and manual dyspraxia were most frequently experienced symptoms. Moreover, 14 (35\%) patients have experienced one or more HCD symptoms in more than one third of their auras.

Patients with HCD during aura were classified as HCD group. The 18 patients who did not experience HCD during aura were classified as Standard aura group. Comparison of demographic data and features of aura between these groups are shown in Table 4. There was no statistically significant difference in terms of gender, age at the time of examination, age at migraine onset and duration of aura. Also, these two groups did not significantly differ in number of patients who reported numbness in arms, face and lips as symptom during the aura. Frequency of aura per year was significantly higher in $\mathrm{HCD}$ group $(6.18 \pm 3.17$ vs. $3.33 \pm 2.03, \mathrm{p}=0.003)$, as well as the number of patients with somatosensory symptoms during aura $(77.3 \%$ vs. $38.9 \%, \mathrm{p}=0.014)$. Also, HCD group had significantly more patients who reported numbness in hands, tongue and legs compared to Standard aura group.

\section{Discussion}

These are the first detailed nosographic descriptions, to our knowledge, of the symptoms experienced during the aura reported by teenagers who have migraine with aura. Our data show that neurological non-visual symptoms, including $\mathrm{HCD}$, during the aura in teenage migraine are notable. Also, the findings of this study clearly demonstrate the variability of aura symptoms. To our opinion, these are important information for pediatricians and other physicians when facing new cases of migraine with unusual aura.

The most common manifestation of migraine with aura is visual phenomenon [14], reported by all our patients. Besides the simple positive or negative phenomena, high number of patients have also reported some form of complex visual disturbances. The most frequent visual

Table 3 Features of HCD during the aura reported in teenage migraineurs

\begin{tabular}{|c|c|c|c|c|}
\hline HCD & $\begin{array}{l}\text { Number of patients } \\
\qquad \mathrm{n}=\mathbf{4 0}(\%)\end{array}$ & $\begin{array}{l}\text { Onset time } X \pm S D \\
(\text { min-max })\end{array}$ & $\begin{array}{c}\text { Time duration } \\
\mathrm{X} \pm \mathrm{SD} \text { (min-max) }\end{array}$ & $\begin{array}{l}\text { Frequency } X \pm S D \\
(\text { min-max })\end{array}$ \\
\hline Color dysgnosia & $8(20)$ & $8.5 \pm 6.48(2-20)$ & $7.13 \pm 6.1(2-20)$ & $60 \pm 40.71(10-100)$ \\
\hline Dysnomia & $3(7.5)$ & $15.67 \pm 14.01(2-30)$ & $15.67 \pm 14.01(2-30)$ & $46.67 \pm 46.19(20-100)$ \\
\hline Retrograde amnesia & $4(10)$ & $16.75 \pm 15.35(2-30)$ & $16.75 \pm 15.35(2-30)$ & $41.25 \pm 21.75(20-70)$ \\
\hline Anterograde amnesia & $2(5)$ & $\mathrm{n} / \mathrm{a}$ & $\mathrm{n} / \mathrm{a}$ & 10 \\
\hline Déjà vu phenomenon & $9(22.5)$ & $20.25 \pm 11.17(2-30)$ & $\mathrm{n} / \mathrm{a}$ & $30.56 \pm 14.24(10-50)$ \\
\hline Expressive dysphasia & $5(12.5)$ & $21 \pm 15.59(3-30)$ & $15.6 \pm 13.39(3-30)$ & $47 \pm 36.33(20-100)$ \\
\hline Gibberish speaking & $2(5)$ & $16.5 \pm 19.09(3-30)$ & $16.5 \pm 19.09(3-30)$ & $45 \pm 35.35(20-70)$ \\
\hline Slowed speech & $11(27,5)$ & $19.75 \pm 19.51(3-60)$ & $18.64 \pm 17.44(2-60)$ & $59.55 \pm 39.9(10-100)$ \\
\hline Dyslexia & $10(25)$ & $21.5 \pm 944(10-30)$ & $21.5 \pm 17.89(3-60)$ & $41.5 \pm 27.49(10-100)$ \\
\hline Dyscalculia & $2(5)$ & $37.5 \pm 31.82(15-60)$ & $25 \pm 28.28(5-45)$ & $30 \pm 28.28(10-50)$ \\
\hline Astereognosis & $2(5)$ & $16.5 \pm 19.09(3-30)$ & $8 \pm 9.9(1-15)$ & $55 \pm 63.64(10-100)$ \\
\hline Manual dyspraxia & $8(20)$ & $21.13 \pm 20.25(4-60)$ & $18.75 \pm 21.96(2-60)$ & $46.88 \pm 37.51(10-100)$ \\
\hline Right-left confusion & $5(12.5)$ & $18.75 \pm 17.97(5-45)$ & $13.6 \pm 17.74(3-45)$ & $51 \pm 45.33(10-100)$ \\
\hline Neglecting hand symptom & $2(5)$ & $17.5 \pm 17.68(5-30)$ & $17.5 \pm 17.68(5-30)$ & $50 \pm 28.28(30-70)$ \\
\hline
\end{tabular}

Onset time - aura onset in regard to beginning of headache expressed in minutes; Time duration - expressed in minutes; Frequency - frequency of symptom compared to all experienced auras (expressed in percentages); n/a - not applicable. 


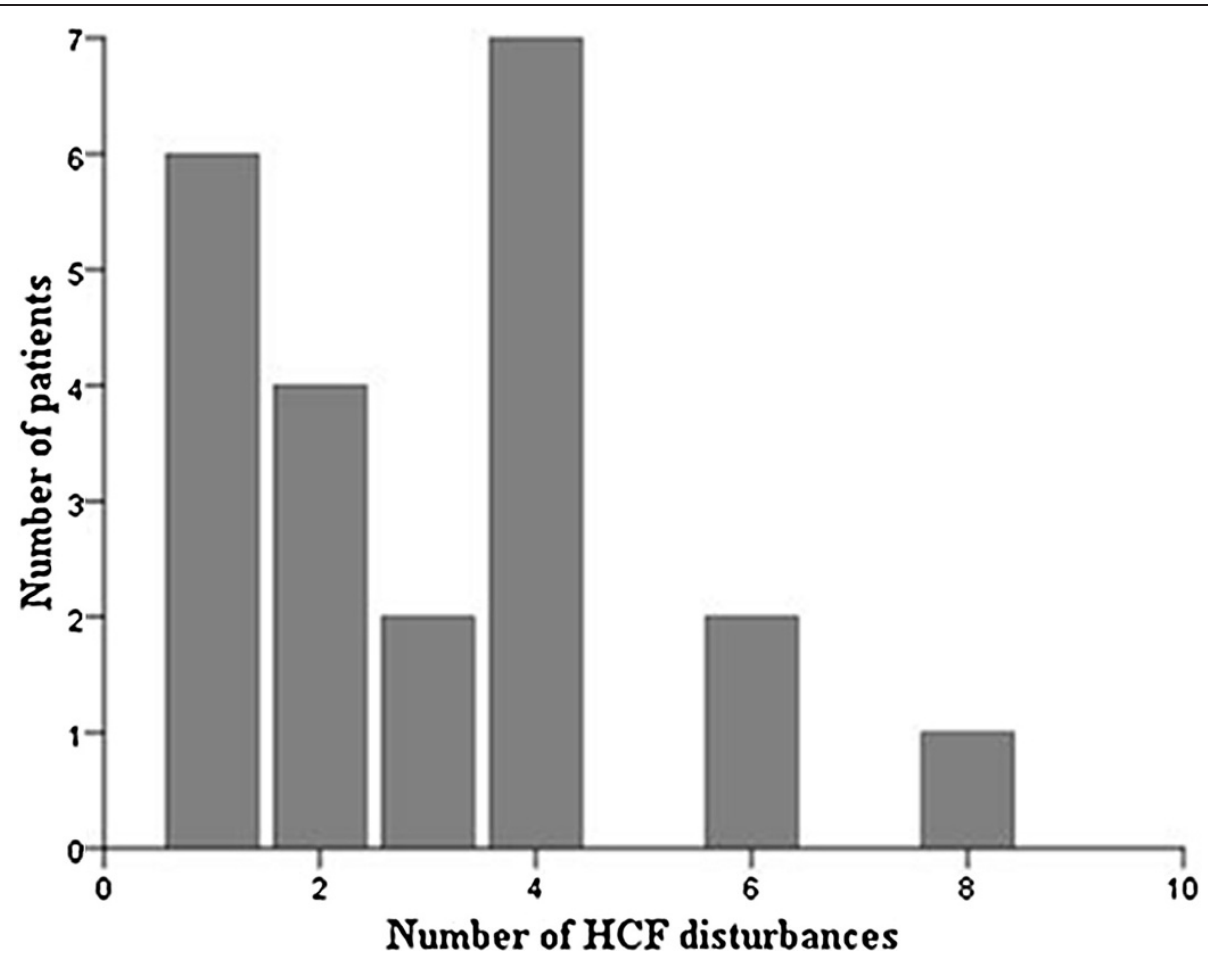

Figure 1 Distribution of patients by number of HCF disturbances. HCF: higher cortical function.

symptom was scintillating scotoma, followed by blurry vision, tunnel vision and zig-zag lines. These symptoms had gradual development which corresponds with typically described migraine aura [13]. High prevalence of blurry vision and tunnel vision (shrinking of visual field) in our patients, not typically considered to be an aura phenomenon of cortical origin, support recent findings towards heterogeneous symptoms of visual aura [15]. Moreover, visual dysgnosia during the aura was frequently reported by our patients in contrast to findings in literature [16]. Color dysgnosia, in terms of this - colors get brighter and patients had difficulties in recognition of color shades, was most commonly reported symptom of visual types of dysgnosia and most frequently experienced symptom in patient auras. This could be explained by the fact that visual auras could arise from the primary visual cortex, as well as from other extrastriate areas (e.g. V2, V3yVP, V3A, and V4v) $[17,18]$. In the other hand, prosopagnosia was reported in only one patient. This could be due to the fact that this function is localized bilaterally [19].

The second most common type of aura in our group of patients was somatosensory phenomena (60\%). The most frequently reported somatosensory symptom was

Table 4 Comparison of demographic data and aura features between HCD group and standard aura group

\begin{tabular}{lccc}
\hline Demographic data, aura characteristics & HCD group $(\mathbf{n}=\mathbf{2 2})$ & Standard aura group $(\mathbf{n}=\mathbf{1 8})$ & Statistics \\
\hline Gender - girls (\%) & $10(45.5)$ & $10(55.6)$ & $16.06 \pm 2.1$ \\
Age of patients, $X \pm S D$, years & $16.32 \pm 1.98$ & $12.17 \pm 2.97$ & $p=0.525$ \\
Age at the time of the onset of migraine, $X \pm S D$, in years & $13.18 \pm 1.74$ & $27.5 \pm 10.04$ & $p=0.212$ \\
Aura duration, $X \pm S D$, in minutes & $30.91 \pm 20.85$ & $3.33 \pm 2.03$ & $p=1.000$ \\
Number of auras per year, $X \pm S D$ & $6.18 \pm 3.17$ & $7(38.9)$ & $p=0.003$ \\
Somatosensory symptoms (\%) & $17(77.3)$ & $5(27.8)$ & $p=0.014$ \\
Numbness in hands (\%) & $16(72.7)$ & $2(11.1)$ & $p=0.005$ \\
Numbness in arms (\%) & $9(40.9)$ & $3(16.7)$ & $p=0.073$ \\
Numbness of the face and lips (\%) & $9(40.9)$ & $1(5.6)$ & $p=0.165$ \\
Numbness of the tongue (\%) & $10(45.5)$ & $0(0)$ & $p=0.011$ \\
Numbness in legs (\%) & $6(27.3)$ & $p=0.024$ \\
\hline
\end{tabular}


numbness in hand (52.5\%), while $15 \%$ of the patients reported numbness in legs with "marching" phenomenon, which is in line with previous similar study in adult population with migraine [20]. Interestingly, patients with visual and somatosensory aura mainly reported 5 to 10 minutes delay of beginning of somatosensory symptoms after beginning of visual aura, but also in eight patients somatosensory aura onset occurred at the same time or before visual aura. These findings could indicate multiple origin of CSD in some of patients, which is previously proposed $[17,20]$. It is noteworthy that all patients had normal imaging examinations that excluded a structural lesion which might either account for or be caused by the hyperexcitability that triggers migraines [21].

Beyond the visual and somatosensory symptoms, phenomena reported during the migraine include misperceptions, impaired gnosis, praxis, and memory [8]. In our study, HCD during the aura were notable. Slowed speech and problems in reading as symptoms during the aura were the most usually reported. Moreover, $36 \%$ of teenage migraineurs had some type of dysphasic disturbances during the aura, which is high in comparison to $15 \%$ reported by Russell MB and Olesen J [16], but less than in our previous study where dysphasic symptoms were reported by $53 \%$ of adults with migraine [11]. Furthermore, in teenagers with migraine symptoms of expressive dysphasia were less common (12\%) in comparison to adult's migraine [14]. We can only speculate that in teenage migraineurs CSD rarely reach Broca's region. Also, in our opinion, it is very important to focus on the diversity of dysphasic presentation among migraineurs in further investigations.

One of ten of our patients had memory disturbances during the aura, such as difficulties in remembering the events or more frequently in recalling past events. In patients who had these symptoms every second migraine aura was accompanied by retrograde amnesia. Memory processes involve regions in the medial temporal lobes including the hippocampus, which may be implicated during CSD [8]. Déjà vu phenomenon was reported by $22.5 \%$ of our patients, mostly in one third of their auras. Also, our patients reported difficulties in calculating, naming, performing precise movements with hands, orienting in space, recognizing objects by touch, as well as neglecting hand symptom. Frequency of all these HCD occurrences point out the variety of possibilities of CSD propagating through the cortex $[8,21]$.

Further, we compared two subgroups of patients who experienced one or more HCD symptoms during the aura (HCD group) and those who did not experienced HCD (Standard aura group). Main findings were that these subgroups did not differ in terms of gender, age of patients, age at the time of the onset of migraine, aura duration and location of the beginning of visual disturbances in the visual field. This is in line with findings in adult migraine population, except for aura duration, where migraineurs with HCD during the aura had significantly longer duration of aura [11]. Also, HCD group has significantly higher number of auras per year compared to Standard aura group. We can only speculate that this could be due to networks immaturity in teenagers with migraine, which is demonstrated in adolescents [22-24]. Also, we found higher prevalence of somatosensory symptoms in HCD group compared to Standard aura group. Furthermore, we can assume that wideness of somatosensory cortex affected region and CSD intake of secondary somatosensory regions is linked to the number and types of HCD, because the somatosensory cortex plays major importance in multisensory integration processes [25-27].

It should be also mentioned that we had ten patients whose migraine aura proceeded after onset of headache for some period of time. This finding could be of interest for further investigation and more deeply understanding of aura features influence on quality of pain.

The main limitations of our study are the facts that data were collected between attacks and that HCD were determined by patients' reports. Nevertheless, as the majority of our patients experienced more than 10 auras with a monthly appearance of aura, we could suppose that their descriptions are relevant. Although complex or less clear cognitive changes are particularly susceptible to recall biases, the results clearly indicate that certain cortical dysfunctions must be largely underestimated in migraine because specific questioning is not part of the routine clinical evaluation.

\section{Conclusions}

The analysis of the present cases and general experience $[8,11,16]$ indicates that aura symptoms, regardless of their form, vary to a great extent in duration and complexity from patient to patient, and also within each individual. Hence, we have concluded from our nosographic analysis of migraine aura in teenagers that higher cortical disturbances should be examined more profound in patients. Also, continuously reporting of aura features in teenagers with migraine with HCD during the aura represent great opportunity for neuroimaging investigation of CSD impact on cortex development in adolescents.

\section{Consent}

Written informed consent was obtained from the patient's parent for the publication of this report.

Competing interests

The authors declare that they have no competing interests. 


\section{Authors' contributions}

IP carried out study design, interviews with patients, analysis and interpretation of data and drafted the manuscript. VP participated in data collection. DV participated in patient selection and provided database of her patients. JJ carried out study supervision, provided database of her patients and revised the manuscript for content. All authors read and approved the final manuscript.

\section{Disclosure}

This work was supported by a grant from the Ministry of Science and Technology of the Republic of Serbia (project no. 41020)

Assoc. Professor Dr. Jancic has received research grant support by the Ministry of Education and Science, Republic of Serbia (project no. 175031)

\section{Author details}

${ }^{1}$ Clinic of Neurology and Psychiatry for Children and Youth, CCS, Doktora Subotica 6a, 11000 Belgrade, Serbia. ${ }^{2}$ Faculty of Medicine, University of Belgrade, Doktora Subotica 8, 11000 Belgrade, Serbia.

Received: 10 October 2014 Accepted: 7 December 2014 Published: 12 December 2014

\section{References}

1. Wöber-Bingöl C (2013) Epidemiology of migraine and headache in children and adolescents. Curr Pain Headache Rep 17:341

2. Rasmussen BK, Olesen J (1992) Migraine with aura and migraine without aura: an epidemiological study. Cephalalgia 12:221-228

3. Hansen JM, Lipton RB, Dodick DW, Silberstein SD, Saper JR, Aurora SK, Goadsby PJ, Charles A (2012) Migraine headache is present in the aura phase: a prospective study. Neurology 79:2044-2049

4. Foroozan R, Cutrer FM (2009) Transient neurologic dysfunction in migraine. Neurol Clin 27:361-378

5. Gelfand AA, Fullerton HJ, Goadsby PJ (2010) Child neurology: migraine with aura in children. Neurology 75:e16-e19

6. Welch KM (1997) Pathogenesis of migraine. Semin Neurol 17:335-341

7. Rogawski MA (2008) Common pathophysiologic mechanisms in migraine and epilepsy. Arch Neurol 65:709-714

8. Vincent MB, Hadjikhani N (2007) Migraine aura and related phenomena: beyond scotomata and scintillations. Cephalalgia 27:1368-1377

9. Schipper S, Riederer F, Sándor PS, Gantenbein AR (2012) Acute confusional migraine: our knowledge to date. Expert Rev Neurother 12:307-314

10. Gantenbein AR, Riederer F, Mathys J, Biethahn S, Gossrau G, Waldvogel D, Sándor PS (2011) Confusional migraine is an adult as well as a childhood disease. Cephalalgia 31:206-212

11. Petrusic I, Zidverc-Trajkovic J, Podgorac A, Sternic N (2013) Underestimated phenomena: higher cortical dysfunctions during migraine aura. Cephalalgia 33:861-867

12. Biedroń A, Steczkowska M, Zajac A, Stolarska U, Kroczka S (2009) Migrainous aura subtypes in hospitalized children. Przegl Lek 66:952-957

13. Headache Classification Committee of the International Headache Society (2004) The international classification of headache disorders, 2nd ed. Cephalalgia 24:1-160

14. Kirchmann M (2006) Migraine with aura: new understanding from clinical epidemiologic studies. Curr Opin Neurol 19:286-293

15. Queiroz LP, Friedman DI, Rapoport AM, Purdy RA (2011) Characteristics of migraine visual aura in Southern Brazil and Northern USA. Cephalalgia 31:1652-1658

16. Russell MB, Olesen J (1996) A nosographic analysis of the migraine aura in a general population. Brain 119:355-361

17. Hadjikhani N, Sanchez Del Rio M, Wu O, Schwartz D, Bakker D, Fischl B, Kwong KK, Cutrer FM, Rosen BR, Tootell RB, Sorensen AG, Moskowitz MA (2001) Mechanisms of migraine aura revealed by functional MRI in human visual cortex. Proc Natl Acad Sci U S A 98:4687-4692

18. Hansen JM, Baca SM, Vanvalkenburgh P, Charles (2013) A Distinctive anatomical and physiological features of migraine aura revealed by 18 years of recording. Brain 136:3589-3595

19. De Renzi E (2000) Disorders of visual recognition. Semin Neurol 20:479-485

20. DaSilva AF, Granziera C, Snyder J, Hadjikhani N (2007) Thickening in the somatosensory cortex of patients with migraine. Neurology 69:1990-1995
21. Granziera C, DaSilva AFM, Snyder J, Tuch DS, Hadjikhani N (2006) Anatomical alterations of the visual motion processing network in migraine with and without aura. PLoS Med 3:e402

22. Konrad K, Neufang S, Thiel CM, Specht K, Hanisch C, Fan J, Herpertz-Dahlmann B, Fink GR (2005) Development of attentional networks: an fMRI study with children and adults. Neuroimage 28:429-439

23. Cepeda C, André VM, Wu N, Yamazaki I, Uzgil B, Vinters HV, Levine MS, Mathern GW (2007) Immature neurons and GABA networks may contribute to epileptogenesis in pediatric cortical dysplasia. Epilepsia 48:79-85

24. Spronk M, Vogel EK, Jonkman LM (2012) Electrophysiological evidence for immature processing capacity and filtering in visuospatial working memory in adolescents. PLoS One 7:e42262

25. Reed CL, Klatzky RL, Halgren E (2005) What vs. where in touch: an fMR study. Neuroimage 25:718-726

26. Renier LA, Anurova I, De Volder AG, Carlson S, VanMeter J, Rauschecker JP (2009) Multisensory integration of sounds and vibrotactile stimuli in processing streams for "what" and "where". J Neurosci 29:10950-10960

27. Theriot JJ, Toga AW, Prakash N, Ju YS, Brennan KC (2012) Cortical sensory plasticity in a model of migraine with aura. J Neurosci 32:15252-15261

doi:10.1186/1129-2377-15-87

Cite this article as: Petrusic et al.: Features of migraine aura in teenagers.

The Journal of Headache and Pain 2014 15:87.

\section{Submit your manuscript to a SpringerOpen ${ }^{\odot}$ journal and benefit from:}

- Convenient online submission

- Rigorous peer review

- Immediate publication on acceptance

- Open access: articles freely available online

- High visibility within the field

- Retaining the copyright to your article

Submit your next manuscript at $>$ springeropen.com 